\title{
Salivary theophylline estimation in the management of asthma in children
}

\author{
S. M. LENA* \\ D.C.H., M.R.C.P. \\ P. HutChins $\dagger$ \\ M.R.C.P. \\ C. B. S. Wood $\dagger$ \\ D.C.H., F.R.C.P. \\ P. TURNER* \\ M.D., B.Sc., F.R.C.P. \\ *Department of Clinical Pharmacology, St Bartholomew's Hospital, London EC1A 7BE and \\ .Queen Elizabeth Hospital for Sick Children, Hackney Road, London
}

\begin{abstract}
Summary
Simultaneous sampling was performed to determine whether saliva could replace plasma in the monitoring of theophylline dosages. Forty-eight children with moderate to severe asthma received oral theophylline preparation (usually sustained release) on a daily basis. They provided simultaneous saliva and plasma samples at routine out-patient visits. Saliva and plasma theophylline concentrations showed a wide variation between individuals, and their ratios also differed. Saliva theophylline concentrations below $7 \mu \mathrm{g} / \mathrm{ml}$ reflect plasma concentrations below $10 \mu \mathrm{g} / \mathrm{ml}$, i.e. sub-therapeutic, while saliva concentrations above $7 \mu \mathrm{g} / \mathrm{ml}$ are consistent with therapeutic dosage.

Estimation of saliva theophylline concentration on routine visits avoids the discomfort of blood sampling. It reflects whether daily oral theophylline dosage in childhood asthma is below or within the therapeutic range. The need for changes in dosage and the degree of patient-compliance with therapy can be usefully indicated.
\end{abstract}

\section{Introduction}

Theophylline has been used in the management of asthma for more than 40 years, although its popularity as a therapeutic agent has varied over the years. Clinical and pharmacological studies have now established suitable dosage regimens on $\mathrm{a} \mathrm{mg} / \mathrm{kg}$ body-weight basis (Jenne et al., 1972; Piafsky and Ogilvie, 1975).

A therapeutic range of $10-20 \mu \mathrm{g} \mathrm{ml}$ of theophylline in plasma is known to give maximal clinical response (Turner-Warwick, 1957; Weinberger and Bronsky, 1974) but toxic side effects may occur even within this range (Hambleton et al., 1977).

Strict adherence to recommended dosages does not, however, invariably result in plasma levels within the therapeutic range, and a significant inter-subject variation in the elimination rate of theophylline in children has been shown (Ellis, Koisooko and Levy, 1976; McKenzie, Baillie and Godfrey, 1978). Therefore, estimating plasma theo- phylline concentrations in children on long-term treatment with theophylline preparations is important. Venepunctures or finger-pricks for the purpose of plasma theophylline estimations in asthmatic children at each of their fortnightly or monthly out-patient visits have many drawbacks.

The purpose of this study was to determine whether salivary theophylline estimations could replace plasma theophylline measurements at routine clinic visits in asthmatic children on long-term therapy with theophylline preparations.

\section{Patients and methods}

Forty-eight asthmatic children receiving theophylline on a long-term basis had simultaneous samples of blood and saliva collected at the outpatient clinic. Thirty-nine of the children attended the asthma and allergy clinic held fortnightly at the Queen Elizabeth Hospital for Children, Hackney Road, London, and the remaining 9 attended a general paediatric clinic held weekly at $\mathrm{St}$ Bartholomew's Hospital. Blood was collected by venepuncture $-2 \mathrm{ml}$ samples from each child - into lithium-heparin tubes. Unstimulated samples of saliva were collected into sterile plastic containers. Blood and saliva samples were centrifuged at the end of each clinic and plasma and mucus-free saliva specimens frozen at $-20^{\circ} \mathrm{C}$ before assay, which was generally within $72 \mathrm{hr}$ of collection. Samples were collected soon after starting theophylline administration to monitor therapeutic dosage and when symptoms suggested a need for dosage modification. Samples were assayed by EMIT (Syva, England), a homogeneous enzyme immuno-assay system which is specific for theophylline. No other xanthine derivatives, their metabolites or drugs likely to be administered concomitantly have been reported to affect the accuracy of this method. Some samples were measured by a gas-liquid chromatography (GLC) method (Dusci, Hackett and McDonald, 1975). This method was modified to the extent that only one $\mathrm{ml}$ of plasma was used and the volume of 
the other reagents was adjusted accordingly. The sensitivity of this assay was $1 \mu \mathrm{g} / \mathrm{ml}$, while that of EMIT was $2.5 \mu \mathrm{g} / \mathrm{ml}$. The coefficients of variation for the EMIT and GLC methods were about 11 and $15 \%$ respectively.

There were 29 boys and 19 girls in the group, with ages ranging from 3 to 16 years. The mean age was 8 years. Thirty-four children were receiving aminophylline sustained release tablets (Phyllocontin, Napp Laboratories), 11 receiving theophylline sustained release capsules (Slophyllin, Rona Laboratories) and 3 of the youngest children received theophylline syrup (Neulin Elixir, Riker Laboratories) for ease of drug administration. Apart from these 3 children, samples were taken 6-9 $\mathrm{hr}$ after the morning dose. A total of 75 samples were collected from the 48 children over a 6-month period. Fourteen per cent. of the children refused to have venepunctures but gave saliva readily. Fifty-five paired samples of saliva and plasma were successfully obtained for analysis. In general, 5-15 min were necessary for collection of saliva samples. Parents, nurses and children had to be instructed that saliva and not sputum coughed up from the bronchi was required. Waiting time after consultation was minimized by giving the sterile plastic containers to the patients to use under the supervision of the parent while waiting to be seen by the doctor.

Weight-for-weight aminophylline preparations contain about $85 \%$ theophylline and the doses of aminophylline sustained release were, therefore, slightly and appropriately greater than those of theophylline alone.
Results

The dose range for the patients studied was from 4-18 $\mathrm{mg} / \mathrm{kg}$ twice daily. Plasma theophylline con 0 centrations ranged from 0 to $25.0 \mu \mathrm{g} / \mathrm{ml}$ and saliva ${ }^{C}$. theophylline from $0-18.5 \mu \mathrm{g} / \mathrm{ml}$ (Fig. 1). Figure $\overrightarrow{2 \mathrm{~F}}$ shows the values of plasma and saliva theophylline from paired samples plotted on the $y$ - and $x$-axese respectively. The correlation coefficient of $0.75 \bar{n}$ obtained was significant at the $1 \%$ level. There was, $\bar{D}$ however, a wide scatter among the data points The majority of plasma points lay below the therapeutic range of $10-20 \mu \mathrm{g} / \mathrm{ml}$. Only one subject, $\vec{O}$ although asymptomatic, had a potentially toxicplasma concentration. The mean plasma/saliva ratio for this group was 1.4 and, using this ratio, ao 'therapeutic range' of 7-17 $\mu \mathrm{g} / \mathrm{ml}$ could be derive for saliva theophylline. Eighty-two per cent. oter observed plasma theophylline levels whose corres-o ponding salivary levels lay below $7 \mu \mathrm{g} / \mathrm{ml}$ were subtherapeutic and, of plasma levels with corresponding $\mathrm{g}_{00}$ saliva levels above $7 \mu \mathrm{g} / \mathrm{ml}, 67 \%$ were within the therapeutic range. Current data are not sufficient to make predictions regarding toxic levels.

\section{Discussion}

Drug level monitoring is particularly useful in the management of patients on continuous therapy, especially in children, and when the therapeusic range of the drug involved is narrow. Blood is usual sample obtained but saliva samples are p ferable for the patient.

The wide disparity between salivary and plasmo theophylline levels in some patients may be due tof

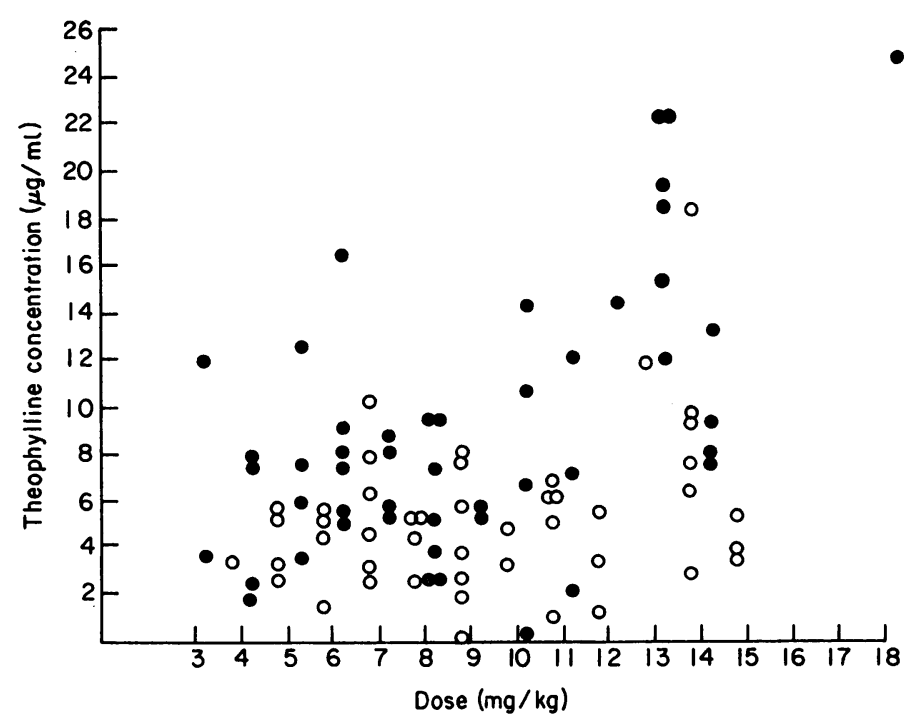

FIG. 1. Concentrations of theophylline in plasma (O) and saliva $(O)$ at different dose ranges in 48 children. 
several factors. Salivary theophylline levels are said by some authors to be unaffected by changes in salivary flow rate (Koysooko, Ellis and Levy, 1974) or by changes in salivary $\mathrm{pH}$ within the physiological range 6.5-8.0 (Mucklow et al., 1978). The concentration of most drugs in saliva probably reflects the

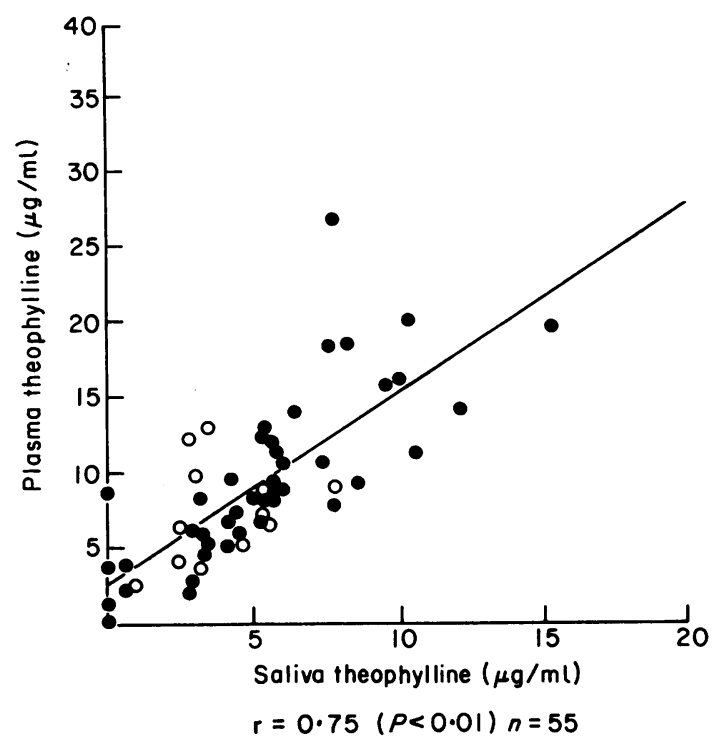

FIG. 2. Paired plasma and salivary theophylline levels $(\mu \mathrm{g} / \mathrm{ml})$, measured by gas-liquid chromatography $(O)$ or by EMIT (O). $r=0.75(P<0.01) n=55$.

unbound fraction of the drug in plasma (Danhof and Breimer, 1978). The free theophylline fraction has been reported to be $85 \%$ but Vallner et al. (1978) have reported that theophylline-binding in plasma is $\mathrm{pH}$-dependent, being significantly lower at pH 7.0 than at 7.4. It is possible that this may contribute to some of the variations seen and is being further investigated. Although the analytical methods used are reasonably good when compared with analyses of other drugs, coefficients of variation between $11-15 \%$ may contribute in part to the disparity. Other factors to be considered are the varying times between drug ingestion and sampling and the possibility of contamination of mouth debris by drug, particularly with the liquid formulation.

Further studies are in progress to establish the reasons for the variation seen in saliva/plasma ratios.

In spite of the considerable scatter observed in the plasma and saliva levels, the saliva 'therapeutic range' (described above) would enable a useful practical prediction to be made as to whether or not a child's plasma theophylline level was in the therapeutic range. A knowledge of this fact would enable the clinician confidently to give a patient the maximal benefit of therapy prescribed or suspect non-compliance if the circumstances warrantit. In addition, saliva theophylline estimations would make clinic visits less traumatic to the child and more economical by the mere savings on syringes, needles and medical time.

The majority of data points in the sub-therapeutic range is an interesting reflection of the caution with which drugs are usually used. A readily applicable and acceptable method of monitoring drug levels such as is described could lead to more appropriate use of this valuable drug.

\section{Acknowledgments}

The authors thank Mrs Sonia Cooke; Mrs J. Wadsworth for help with statistical analysis; the Peel Medical Research Trust for financial support. S.M.L. is in receipt of a research grant from Hoechst Pharmaceuticals Ltd.

\section{References}

DANhof, M. \& BReimer, D.D. (1978) Therapeutic drug monitoring in saliva. Clinical Pharmacokinetics, 3, 37.

DusCI, L.J., HACKeTt, L.P. \& MCDonALD, I.A. (1975) Gas-liquid chromatographic determination of theophylline in human plasma. Journal of Chromotography, 104, 147.

Ellis, E.F., Koysooko, R. \& LeVY, G. (1976) Pharmacokinetics of theophylline in children with asthma. Pediatrics, 58, 542.

Hambleton, G., Weinberger, M., Taylor, J., Cavanaugh, M., Ginchansky, E., Godfrey, S., Tooley, M., Bell, T. \& GREenberG, S. (1977) Comparison of cromoglycate (cromolyn) and theophylline in controlling the symptoms of chronic asthma. Lancet, $i, 381$.

JenNe, J.W., Wyze, E., Rood, F.S. \& McDonald, F.M. (1972) Pharmacokinetics of theophylline: application to adjustment of the clinical dose of aminophylline. Clinical Pharmacology and Therapeutics, 13, 349.

Koysooko, R., Ellis, E.F. \& LeVy, G (1974) Relationship between theophylline concentration in plasma and saliva of man. Clinical Pharmacology and Therapeutics, 15, 454.

MCKenzie, S.A., Baillie, E. \& Godfrey, S. (1978) Effect of practical turning of dosage of theophylline blood levels in asthmatic children treated with choline theophyllinate. Archives of Disease in Childhood, 53, 167.

Mucklow, J.C., Bending, M.R., KaHN, G.C. \& Dollery, C.T. (1978) Drug concentration in human saliva. Clinical Pharmacology and Therapeutics, 24, 563.

Piafsky, K.M. \& OGILvie, R. (1975) Dosage of theophylline in bronchial asthma. New England Journal of Medicine, 292, 1218.

TURNER-WARWICK, M. (1957) Study of theophylline plasma levels after oral administration of new theophylline compounds. British Medical Journal, 2, 67.

Vallner, J.J., Speir, W.A., Kolbeck, R.C., Harrison, G.N. \& BRANSOME, E.D. (1978) Effect of pH on plasma protein binding of theophylline. American Review of Respiratory Diseases, 117, 1885.

WEINBERGER, M.M. \& BroNSKy, E.A. (1974) Evaluation of oral bronchodilator therapy in asthmatic children. Journal of Pediatrics, 84, 421. 